\title{
NOVOS PARADIGMAS DE DIREITOS SOCIAIS E A DIGNIDADE DA PESSOA HUMANA, ANALISADA SOB O ENFOQUE DO DIREITO DE PERSONALIDADE DO TRABALHADOR EM UM MUNDO GLOBALIZADO
}

\section{NEW PARADIGMS OF SOCIAL RIGHTS AND HUMAN DIGNITY, ANALYZED FROM THE PERSPECTIVE OF THE RIGHTS OF PERSONALITY OF WORKERS IN A GLOBALIZED WORLD}

\author{
${ }^{1}$ Marco Antônio Cesar Villatore \\ ${ }^{2}$ Marcelo Rodrigues
}

\section{RESUMO}

Analisar-se-ão novos paradigmas de Direitos Sociais em relação à dignidade da pessoa humana, principalmente na situação em que o trabalhador é aviltado em sua moral em razão da globalização, que pode gerar facilmente desemprego. Primeiramente se fará uma diferenciação, ou não, dos Direitos Sociais em relação a outros Direitos. Abordar-se-á, também, a questão da globalização com a abordagem da crise econômica como fator que gera problemas diretos e indiretos em todo o mundo. O objetivo principal será apontar a saída para tal situação preocupante. A metodologia empregada será a de pesquisa bibliográfica e estudo da legislação.

Palavras-chave: Direitos Sociais; Dignidade da pessoa humana; Direito de Personalidade; Globalização; Crise Econômica.

\begin{abstract}
New paradigms of social rights in relation to human dignity will be analyzed, principally in situations in which workers are morally degraded because of globalization, by virtue of its ready generation of unemployment. First, the distinction (or lack thereof) will be examined with respect to social rights in relation to other rights. The question of globalization will also be considered, emphasizing the economic crisis as a factor that directly and indirectly produces problems everywhere. The primary objective will be to point to a solution to such a troubling situation. The methodology used will be bibliographic research and analysis of legislation.
\end{abstract}

Keywords: Social rights; Human dignity; the rights of personality; globalization; Economic crisis.

\footnotetext{
${ }^{1}$ Pós-Doutor pela Universidade de Roma Tor Vergata (UNIROMAII), Roma, Itália. Professor Titular de Direito do Trabalho pela Pontifícia Universidade Católica do Paraná (PUCPR), Curitiba, Paraná, Brasil. Email: marcovillatore@ gmail.com ${ }^{2}$ Mestrando em Direito pela UNIBRASIL. Especialista pela Pontifícia Universidade Católica do Paraná (PUCPR), Curitiba, Paraná, Brasil. Email: marcelorodrigues31052@gmail.com
} 


\section{INTRODUÇÃO}

Este trabalho visa, em um primeiro momento, fazer uma diferenciação, ou não, entre Direitos Sociais, Direitos Humanos, Direitos Fundamentais e, por fim, chegando ao Direito de Personalidade, além da intimidade e da privacidade do trabalhador.

Após isso, será abordada a questão sobre os efeitos da Globalização e a empregabilidade, mas recordando que o empregador pode visar o lucro, sem que necessite abusar do seu trabalhador, que desempenha sua atividade funcional.

A novidade no presente estudo é a preocupação atual com a crise econômica que o Brasil vem passando, fazendo com que alguns maus empregadores se aproveitem da grande procura de pessoas capacitadas e que tenham perdido seus empregos, e acabam exigindo de seus empregados atividades além de suas forças físicas e mentais.

Em contrapartida, os empregados que se mantém em atividade com empregadores que alertam sobre problemas financeiros com a crise, ou para novos empregos em que aqueles, mesmo sem a pressão direta do empregador, acabam ultrapassando esses limites individuais para se destacar e manter a sua fonte de renda.

Pior ainda é a competição entre os empregados, tanto na pressão do empregador, quanto na segunda hipótese supracitada, em que o meio ambiente laboral se torna um local insuportável, gerando muitas vezes um licenciamento do empregado, devido ao seu grau de estresse.

Para cumprir essa tarefa, utilizou-se de metodologia baseada em pesquisa bibliográfica e análise da legislação brasileira, buscando demonstrar que a crise econômica capitalista é cíclica e sua culpa não pode ser atribuída à rigidez da norma trabalhista, mas não se pode descuidar da atenção ao trabalhador, para não gerar mais danos ao ambiente laboral, muitas vezes, inclusive, gerando problemas físicos e morais a este, prejudicando também o mau empregador.

Passa-se à análise dos conceitos supracitados: 


\section{CONCEITOS}

Roland Hasson (2007, p. 40) explica que "muito mais que mera atividade econômica, o trabalho representa a projeção individual no mundo globalizado, tratando-se da inserção do ser humano nos fluxos de geração e distribuição de riqueza".

\subsection{DIREITOS SOCIAIS, DIREITOS HUMANOS E DIREITOS FUNDAMENTAIS}

Importantíssima é a diferenciação dos Direitos Sociais, dos Direitos Humanos e dos

Direitos Fundamentais.

\subsubsection{Direitos Sociais}

Os Direitos Sociais, conforme José Afonso da Silva (2010, p. 286-287), são definidos como prestações positivas proporcionadas pelo Estado direta ou indiretamente, enunciadas em normas constitucionais, que possibilitam melhores condições de vida aos mais fracos, direitos que tendem a realizar a igualização de situações sociais desiguais. São, portanto, direitos que se ligam ao direito de igualdade. Valem como pressupostos do gozo dos direitos individuais na medida em que criam condições materiais mais propícias ao auferimento da igualdade real, o que, por sua vez, proporciona condição mais compatível com o exercício efetivo da liberdade.

A igualdade é bem lembrada no ordenamento jurídico brasileiro, mas não meramente em seu viés formal, sendo necessário salientar que uma das tarefas do Estado brasileiro é a busca da igualdade material, sendo que a efetivação dos Direitos Sociais constitui uma forma de materializar tal fim.

De acordo com Luis Roberto Barroso (2009, p. 10):

O Estado constitucional de direito gravita em torno da dignidade da pessoa humana e da centralidade dos direitos fundamentais. A dignidade da pessoa humana é o centro de irradiação dos direitos fundamentais, sendo frequentemente identificada como o núcleo essencial de tais direitos. 
Vicente Paulo e Marcelo Alexandrino (2012, p. 253) explicam que os Direitos Sociais, por exigirem disponibilidade financeira do Estado para sua efetiva concretização, estão sujeitos à denominada cláusula de reserva do possível, ou, simplesmente, reserva do possível. Essa cláusula, ou princípio implícito, tem como consequência o reconhecimento de que os direitos sociais assegurados na Constituição devem, sim, ser efetivados pelo Poder Público, mas na medida exata em que isso seja possível. É importante entender que esse princípio não significa um 'salvo conduto' para o Estado deixar de cumprir suas obrigações sob a alegação genérica de que 'não existem recursos suficientes'. A não efetivação, ou efetivação apenas parcial, de direitos constitucionalmente assegurados somente se justifica se, em cada caso, for possível demonstrar a impossibilidade financeira (ou econômica) de sua concretização pelo Estado.

\section{Já Clèmerson Merlin Clève (2011, p. 35) explica que:}

O liberalismo foi a doutrina política que fundamentou a construção da teoria do Estado de Direito. Um Estado juridicamente limitado pela Constituição e ideologicamente assumido pela doutrina liberal. Cuidava-se de garantir a liberdade do indivíduo e da sociedade frente ao Estado. De qual liberdade se tratava? Por certo que não daquela dos antigos que conduzia à técnica da participação dos cidadãos no processo político (democracia), senão uma nova concepção de liberdade que conduzia à demarcação de importante esfera de autonomia do cidadão (e da sociedade) contraposta àquela do Estado. $\mathrm{O}$ 'objetivo dos antigos era a distribuição do poder político entre todos os cidadãos de uma mesma pátria: era isso que eles chamavam de liberdade. O objetivo dos modernos é a segurança das fruições privadas: eles chamam de liberdade as garantias acordadas pelas instituições para aquelas fruições.

Flávia Piovesan (2012, p. 401-403), por sua vez, afirma que:

Em síntese, extraem-se do sistema constitucional de 1988 os delineamentos de um Estado intervencionista, voltado ao bem-estar social. (...) As Constituições tendem a se transformar num pacto de garantia social. Assim, o Estado Constitucional Democrático de 1988 não se identifica com um Estado de direito formal, reduzido a simples ordem de organização e processo, mas visa a legitimar-se como um Estado de justiça social, concretamente realizável.

Não se tem dúvida que os Direitos Sociais são o gênero, do qual os demais ramos passam a ser as espécies.

\subsubsection{Direitos Humanos}

Dinaura Godinho Pimentel Gomes (2015, p. 35) apresenta um ótimo histórico:

Convém relembrar desde logo que a institucionalização universal dos Direitos Humanos resultou de grandes lutas, sofrimentos e mortes, historicamente demarcados na era Hitler. Por meio do movimento internacional de reconstrução dos direitos humanos, então violados, buscou-se garantir, 
permanentemente, os valores da igualdade e da liberdade, mediante a satisfação das condições de subsistência digna e decorosa de toda e qualquer pessoa, sem nenhuma distinção.

Os Direitos Humanos são aqueles consagrados nos Tratados Internacionais e direcionados a todas as pessoas pelo simples fato de ostentarem a condição humana, conforme Fabio Konder Comparato (2003, p. 12), e são decorrência direta do princípio da dignidade da pessoa humana presente na Declaração Universal de 1948 e consolidado pela Declaração de Direitos Humanos de Viena de 1993.

Candy Florêncio Thomé (2012, p. 140) explica que "os direitos humanos, dentro dos quais está inserido o direito à igualdade, têm características nucleares a universalidade, indivisibilidade e interdependência", que estão previstas na Declaração Universal dos Direitos Humanos de 1948.

Para a efetiva garantia dos Direitos Humanos se exige que os direitos civis, políticos e sociais sejam acessíveis a todos os cidadãos.

\subsubsection{Direitos Fundamentais}

Arion Sayão Romita (2005, p. 36) afirma que "direitos fundamentais (...) os que, emdado momento histórico, fundados no reconhecimento da dignidade da pessoa humana, asseguram a cada homem as garantias de liberdade, igualdade, solidariedade, cidadania e justiça".

O mesmo autor (Romita, 2005, p. 36) amplia o conceito afirmando que "poderiam ser acrescentadas as notas acidentais de exigência do respeito a essas garantias por parte dos demais homens, dos grupos e do Estado e bem assim a possibilidade de postular a efetiva proteção do Estado em caso de ofensa".

Eduardo Biacchi Gomes e Aline Ferreira Montenegro (2013, p. 129) já bem resumiram as diferenças entre os supracitados institutos, da seguinte forma:

A utilização das expressões "direitos fundamentais" e "direitos humanos" enquanto sinonímias se faz um tanto quanto normal, principalmente por aqueles que não possuem um conhecimento técnico a respeito do tema, todavia há uma diferença latente entre as duas acepções de direitos. Enquanto os direitos fundamentais são específicos para cada ordenamento jurídico, ou seja, cada ordem jurídica possui o seu rol de direitos fundamentais, os direitos humanos, ao menos em tese, são estendidos a 
todos àqueles que gozam da condição de ser humano, sendo, desse modo, dotados de universalidade, extrapolando as barreiras de um país, tendo, por isso, caráter supranacional (...).

Outro ponto de grande discussão é se os Direitos Sociais são ou não cláusulas pétreas constitucionais, como comentado por Gilmar Mendes e Paulo Branco (2014, p. 139-140):

De outro lado, argui-se que os direitos sociais não podem deixar de ser considerados cláusulas pétreas. No Título I da Constituição (Dos Princípios Fundamentais) fala-se na dignidade da pessoa humana como fundamento da República e essa dignidade deve ser compreendida no contexto também das outras normas do mesmo Título em que se fala no valor social do trabalho, em sociedade justa e solidária, em erradicação da pobreza e marginalização e em redução de desigualdades sociais.

Tudo isso indica que os direitos fundamentais sociais participam da essência da concepção de Estado acolhida pela Lei Maior. Como as cláusulas pétreas servem para preservar os princípios fundamentais que animaram o trabalho do constituinte originário e como este, expressamente, em título específico da Constituição, declinou tais princípios fundamentais, situando os direitos sociais como centrais para a sua ideia de Estado democrático, os direitos sociais não podem deixar de ser considerados cláusulas pétreas. No inciso IV do $\S 4^{\circ}$. do art. 60, o constituinte terá dito menos do que queria, terá havido uma "lacuna de formulação", devendo-se ali ler os direitos sociais, ao lado dos direitos e garantias individuais.

Flávia Piovesan (2012. p. 406-407) explica que:

Relativamente ao alcance universal dos direitos humanos, o princípio da dignidade humana, como princípio fundamental da Carta de 1988, por si só, sustenta a concepção de que os direitos humanos decorrem da dignidade inerente a toda e qualquer pessoa, sem qualquer discriminação. $\mathrm{O}$ texto enfatiza que todos são essencialmente iguais e assegura a inviolabilidade dos direitos e garantias fundamentais.

Roland Hasson (2007, p. 49-50) já alertava, que a "maior preocupação é garantir a integração do indivíduo às raias do sistema de inclusão e expansão capitalista, fundindo-se a realização econômica com aspectos inerentes à dignidade e existência humana. Então, percebe-se que a dignidade da pessoa humana se confunde com a atividade econômica por ela exercida, bem como pela possibilidade de estabilidade no desenvolver dessa mesma atividade, impedindo-se que haja qualquer evento que provoque o rompimento na inclusão do indivíduo à teia de consumo, geração e distribuição de riqueza". 


\subsection{DIREITO DE PERSONALIDADE DO TRABALHADOR}

Ronald Silka de Almeida e Marco Antônio César Villatore (2013, p. 112) afirmam que o termo personalidade, de imediato leva ao raciocínio da existência da pessoa e aquilo que é inerente à mesma, o seu caráter, suas ideias, seu conteúdo ético e moral, a forma com que se interrelaciona com o meio em que vive "habita", enfim o seu caráter social, que faz ecoar e que transmite a toda a sociedade.

Mesmo por que a palavra "persona", tem sua origem na linguagem teatral da antiguidade romana, e que significava máscara, que tinha por objetivo dar eco às palavras dos atores. Portanto "persona" queria afirmar máscara, que fazia ressoar a voz da pessoa (MONTEIRO, 1982, p. 55).

Ao fundamentar na República brasileira a cidadania e a dignidade da pessoa humana, conforme o artigo $1^{\circ}$., incisos II e III, respectivamente, complementado pelo artigo $5^{\circ}$., inciso X, todos da Constituição de 1988, encontramos a Teoria dos Direitos da Personalidade.

Marcelo Ivan Melek e Luiz Eduardo Gunther (2013, p. 80) já afirmavam que:

Os Direitos da Personalidade, advindo do direito civil, são uma base comum a todos os ramos da Ciência do Direito. Isso se deve pelo fato de que tais direitos representam garantias ao cidadão, sem as quais a vida em sociedade seria seriamente comprometida ou mesmo inviabilizada, de acordo com os preceitos constitucionais vigentes.

O mesmo autor Luiz Eduardo Gunther (2008, p. 162), em outro estudo, traz classificações aos Direitos de Personalidade do Trabalhador, explica que buscam proteger e efetivar os seguintes direitos:

1) o direito à integridade física - direito à vida, direito ao corpo vivo, direito ao corpo morto; 2) direito à integridade intelectual; 3) direito à integridade moral.

Historicamente, no século III a. C., em seus estudos, Aristóteles (2000, p. 166-167) definia a personalidade como decorrente da coragem, justiça e virtude, sendo que esta última definia de forma absoluta o modo de vida da pessoa, seria ele "senhor" ou "servo", 
“dominador" ou "dominado", e assim estaria definida a sua ética e moral, que assim descreve: “o dirigente então deve ter a virtude ética por inteiro; pois sua tarefa é liderar e a razão lidera. E os outros membros devem ter o montante apropriado a cada um. Assim, é evidente que cada classe mencionada deve ter virtude ética”.

Continuando no campo filosófico, para Kant (Immanuel Kant - filósofo prussiano 1724 - 1804) a personalidade está diretamente ligada à educação, a certeza e a clareza de conhecimentos e "a moral é já por si mesma uma prática no sentido objetivo, enquanto totalidade de leis que ordenam incondicionalmente, de acordo com as quais devemos agir" (2005, p. 79).

Para Nietzsche (Friedrich Nietzsche - filósofo alemão - 1844 - 1900) em seu escrito “para a Genealogia da Moral”, de 1887, a personalidade está ligada à moral, e conforme esclarece Antonio Edmilson Paschoal em seu estudo o filósofo alemão (Nietzsche) define a personalidade como resultante de "ação de forças que tornaram possível o processo de moralização do homem, admitindo, por princípio, que tais forças não podem ser desconsideradas quando se entende o homem como um animal ainda não acabado, e sim um feixe de sempre novas possibilidades que precisa de tais forças para seguir em sua aventura" (PASCHOAL, 2003, p. 49).

No direito europeu, principalmente na Bélgica (MENDES, 2008, p. 378), compreende-se que o desenvolvimento da personalidade humana está diretamente ligada ao termo "vida privada", haja vista que se estende para o "direito de viver como se quer, livre de publicidade, para incluir também o direito de estabelecer e desenvolver relações com outros seres humanos, especialmente no campo emocional, para o desenvolvimento da própria personalidade".

Com a Declaração Universal de 1948, conforme explica Gilmar Ferreira Mendes (2008, p. 254), ganha impulso a tendência de universalização da proteção aos direitos dos homens", ou seja, os direitos fundamentais que antigamente tinham como objetivo proteger (uma classe, um grupo social) o exercício de um direito político ou social, um melhoramento das condições de vida ou de trabalho, passaram a proteger o próprio homem.

Os estudos demonstram que os direitos de personalidade que eram apenas objeto de estudo filosófico, atualmente se enquadram em direitos fundamentais de terceira geração, isto 
baseado na ordem histórico cronológica do desenvolvimento do direito constitucional, ou seja:

a) direitos de primeira geração: estão incluídas as liberdades públicas e os direitos e garantias individuais clássicas (direitos civis e políticos), que surgiram a partir da Magna Carta (MORAES, 2002, p. 39). Conforme esclarece Gustavo Filipe Barbosa Garcia (2009, p. 55), “assim, nas Declarações de Direito do século XVIII, ganham destaque os direitos de 'liberdade', no sentido de que o Estado deve abster-se de interferir na conduta dos indivíduos";

b) de segunda geração: correspondem aos direitos econômicos, sociais e culturais, envolvendo uma prestação positiva do Estado (FERREIRA FILHO, 2005, p. 49-50), como o direito ao trabalho, à educação, à saúde, direitos trabalhistas e previdenciários, bem como os econômicos e culturais garantidores da liberdade das nações e das normas internacional de convivência, surgiram no início do século XX (CAVALCANTI, 1966, p. 202); e

c) de terceira geração: também denominados direitos de solidariedade ou fraternidade, que englobam o direito a um meio ambiente equilibrado, uma saudável qualidade de vida, ao progresso, a paz, a autodeterminação dos povos e a outros direitos difusos (MOTA; SPITZCOVSKI, 2000, p. 316-317).

Aliás, conforme esclarece Alexandre de Moraes (2002, p. 56), efetuando a análise da questão através de uma filtragem constitucional (SCHIER, 1999, p. 67) a personalidade está inserida dentro da soma de elementos que se traduzem nos direitos humanos fundamentais, ou seja, é o "conjunto institucionalizado de direitos e garantias do ser humano que tem por finalidade básica o respeito a sua dignidade, por meio de sua proteção contra o arbítrio do poder estatal e o estabelecimento de condições mínimas de vida e desenvolvimento da personalidade humana".

Esclarece Orlando Gomes (2000, p. 148), que "sob a denominação de direitos de personalidade, compreendem-se direitos considerados essenciais a pessoa humana, que a doutrina moderna preconiza e disciplina, a fim de resguardar a sua dignidade”.

Assim, diante de um dos principais pressupostos norteadores dos direitos humanos a proteção à integridade física e moral, foi albergada através do disposto no Inciso X do artigo $5^{\circ}$., da Constituição de 1988, que assim dispõe: "são invioláveis a intimidade, a vida privada, a honra a imagem das pessoas, assegurado o direito a indenização pelo dano material ou moral decorrente de sua violação".

Portanto de acordo com Luís Roberto Barroso (2008, p. 37-38) "o princípio da dignidade da pessoa humana identifica um espaço de integridade moral a ser assegurado a todas as pessoas por sua só existência no mundo". 
O que leva à constatação de que a proteção à "integridade física ou moral", está diretamente ligada à personalidade, à vida e à dignidade da pessoa humana, consequentemente se desdobrando no que diz respeito às condições mínimas de sobrevivência, e neste sentido deve ser incluído o direito ao trabalho remunerado, habitação, saúde, alimentação, educação, lazer, conforme estipula o artigo 6º . Da Constituição de 1988 , enfim os direitos e garantias fundamentais, são parte integrante da composição da dignidade humana.

\subsection{INTIMIDADE OU PRIVACIDADE}

Alice Monteiro de Barros (1997, p. 27) explica o seguinte: “em português, os termos privacidade e intimidade são sinônimos, constituindo elementos necessários à convivência entre os homens".

Adriana

Calvo

(Disponível

em:

<http://72.14.205.104/search?q=cache:j_oseH6qLYcJ:www.calvo.pro.br/palestras/confli to_poder.pdf+significa+a+esfera+mais+\% C3\% ADntima,+mais+subjetiva+e+mais\&hl= pt-BR\&ct=clnk\&cd=1\&gl=br $>$. Acesso em: 20 de setembro de 2016) diferencia as duas figuras, da seguinte forma:

Intimidade: qualquer pessoa tem, em qualquer lugar onde se encontre, pois ela significa a esfera mais íntima, mais subjetiva e mais profunda do ser humano, com as suas concepções pessoais, seus gostos, seus problemas, seus desvios, etc.

Privacidade: é uma forma de externar essa intimidade, que acontece em lugares onde a pessoa esteja ou se sinta protegida da interferência de estranhos, como a casa onde mora.

Há, portanto, uma diferenciação entre os institutos, fazendo com que possamos estudar de uma forma mais concreta o fenômeno da globalização e os direitos dos trabalhadores. 


\section{GLOBALIZAÇÃO}

Como já explicado por Alexandre Euclides Rocha e Marco Antônio César Villatore (2007, p. 175-177) a situação atual, não somente no Brasil, mas sim na maioria dos países, caracterizado pela escassez de trabalho e pelo excesso de oferta de mão de obra, somado a grande volatilidade dos capitais, traz como consequência um desrespeito aos Direitos Fundamentais, incluindo nestes o Direito à Intimidade do empregado e, da mesma forma, uma disseminação de controles vexatórios, pois a política e o mercado estão marcados por atitudes desumanas e nada éticas, predominando a arrogância, o interesse individual e a exploração descompromissada da mão de obra humana, tudo em "nome da produtividade.

Marcelo Ivan Melek e Luiz Eduardo Gunther (2013, p. 80) explicam o seguinte:

com o objetivo centrado na maximização de lucros e à geração e concentração da riqueza, esta nova fase de expansão do capitalismo global seria particular por ter conferido papel secundário ao ser humano, como agente e beneficiário desse processo. Assim, muitas vezes, em nome dessa "corrida de mercado" descumprem-se normas, desrespeitam-se princípios que visam garantir a valorização do trabalho, em dissonância com os Direitos da Personalidade que visam, dentre outros, assegurar o direito a uma existência digna.

Os mesmos autores (MELEK; GUNTHER, 2013, p. 80) complementam afirmando Por fim, compreender e refletir acerca dos Direitos da Personalidade na perspectiva trabalhista, precisamente na relação contratual, é contribuir para o alargamento da aplicação neste campo do Direito.

A incidência de Danos Morais nas relações de trabalho tem aumentado cada vez mais muito em função do processo de globalização dos últimos anos que foi o responsável pela competitividade empresarial. Assim, a necessidade de destaque no ambiente de trabalho, a fim de ocupar cargos com níveis salariais mais elevados e também a necessidade de garantia de emprego, tem feito com que muitos trabalhadores usem de artifícios psicológicos cada vez mais violentos na disputa com seu colega de profissão.

Mesmo com tal gravidade do fenômeno, muito pouco se foi feito até o momento para o banimento do Dano Moral no ambiente laboral das organizações. 


\section{NOVIDADES QUE DEVEM CHEGAR NA CRISE}

Toda a história do capitalismo é permeada por crises econômicas. Apenas no século XX e início do XXI é possível enumerar uma série de episódios no âmbito mundial sendo absolutamente inviável elencar todos os eventos registrados ao redor do globo terrestre em esferas regionais. Conclusão: crises econômicas são indissociáveis do sistema capitalista (VILLATORE; BOSKOVIC, 2010, p. 51-52).

No rol dos dados apontados na referida matéria acerca do ambiente de trabalho brasileiro, consta que existe outra característica desse mercado, anterior à crise, que continua presente e gera menor impacto social e econômico na crise, por não haver mudança, que é, segundo expõe: “....a precarização, aliada à alta rotatividade de trabalhadores: $62,82 \%$ dos trabalhadores sem carteira assinada, 31,85\% dos trabalhadores autônomos e 17,47\% dos empregados mudaram de posição em um período de apenas 12 meses (FGV) (https://www.google.com/\#q=\%E2\%80\%9C....a+precariza\%C3\%A7\%C3\%A3o\%2C+aliada+ $\% \mathrm{C} 3 \% \mathrm{~A} 0+$ alta+rotatividade+de+trabalhadores:+62\%2C $82 \% 25+\mathrm{dos}+$ trabalhadores+sem+cart eira+assinada $\% 2 \mathrm{C}+31 \% 2 \mathrm{C} 85 \% 25+$ dos + trabalhadores+aut $\% \mathrm{C} 3 \% \mathrm{~B} 4$ nomos+e+17\%2C $47 \% 25$ +dos+empregados+, acessado em 20 de setembro de 2016).

Ainda com relação à geração de emprego e renda, em evento ocorrido no dia 22.09.2010, o “X Encontro Nacional de Estudos Estratégicos” (ENEE), em Brasília, o então Ministro Carlos Lupi, mencionado por Marco Villatore e Alessandra Boskovic, afirma que "Durante a crise, geramos 1,7 milhão de empregos formais, enquanto EUA perderam 6,5 milhões de empregos e Europa perdeu 10,2 milhões de empregos em 2009. No Brasil tivemos também um ganho real de $64 \%$ no salário acima da inflação, e $36 \%$ de ganho real no salário de admissão" (VILLATORE; BOSKOVIC, 2010, p. 52).

Entre as medidas legais adotadas com o objetivo de reduzir os custos de produção e, desta forma, gerar os mecanismos necessários ao combate dos efeitos da crise, a primeira a ser intentada pelas organizações empresariais, foi a redução da jornada e de salários pela via das negociações coletivas, amparadas pelo artigo $7^{\circ}$., inciso VI da Constituição de 1988. 
Entretanto, a questão que deve também ser levada em conta no que se refere às negociações, principalmente em período de turbulências econômicas, é com relação à capacidade financeira das próprias organizações empresariais em manter em dia suas obrigações com a folha de salários, uma vez que estas são as primeiras a sofrer os efeitos das crises, seja pela queda no volume de vendas, seja pela inadimplência que, em muitos casos, torna-se uma consequência involuntária do próprio momento econômico.

Quando se trata de negociação, necessário se faz que o Governo Federal, não menos interessado e principal responsável em proporcionar mecanismos de combate à crise econômica na sociedade.

Uma antiga forma, mas primordial foi na questão de negociação coletiva, com os limites tanto no artigo 503 da CLT e, depois, com a Lei 4.923/1965.

Outra intermediária, foi na atividade rural, foi um caso de redução de encargos sociais patronais, principalmente a sua quota do Instituto Nacional do Seguro social (INSS), para que se facilite a aplique a formalização de empregos, dando inclusive mais segurança jurídica aos empregados. Trata-se de um "Pacto de Solidariedade", definição esta atribuída por Marco Antônio $\quad$ César $\quad$ Villatore (http://www.calvo.pro.br.artigo.marco_villatore_consorcio_simplificado.pdf. Acessado em 20 de setembro de 2016, 2009, p. 430-454).

Mais atualizado é o Programa de Proteção ao Emprego, advindo com a Lei 13.189, e 19 de novembro de 2015, para empresas em situação de dificuldade econômico-financeira, com adesão até 31 de dezembro de 2016, mas com a extinção ocorrendo no fim de 2017, priorizando àquelas que observam a cota de pessoa com deficiência, reduzindo-se até $30 \%$ da remuneração do empregado, mas sempre respeitando o salário mínimo, com duração de até 6 meses, prorrogáveis por iguais períodos, até o total de 24 meses, além da garantia no emprego pelo prazo mais $1 / 3$ daquele firmado entre as partes.

Importante que o Estado faça a sua parte para se manter, pelo menos parcialmente, o nível de vida dos cidadãos em geral, pois facilmente se nota que o desemprego é cíclico e com ele, individualmente analisando, passasse a um círculo vicioso, sem muita chance de se sair senão a longo prazo. 


\section{CONSIDERAÇÕES FINAIS}

Atualmente os cidadãos estão constantemente ligados a algum tipo de pressão, em que os empregadores devem se proteger de seus concorrentes, ora sendo praticado pelo próprio Governo, com tributos exagerados e serviços ineficientes, ora pelas crises políticas e econômicas que se multiplicam tanto dentro quanto fora do país, trazendo total insegurança para seus negócios.

A subordinação hierárquica existente no ambiente do trabalho permite que o empregador transmita suas angústias e agruras para seus subordinados, que, já vivendo em um sistema de pressões sociais, familiares, econômicas, etc., pode se tornar vítima de um modelo perverso e desmedido.

A sociedade mundial está levando o capitalismo a um extremo (especialmente após o fim do comunismo europeu) e tal fato traz consequências nefastas, visíveis hoje no que se refere ao meio ambiente (alterações no clima mundial, buracos na camada de ozônio, secas, inundações, furacões e "tsunamis") e, igualmente, visível no que se refere aos seres humanos (estresse, depressões, desrespeitos múltiplos, etc.), gerando nas relações de trabalho uma série de problemas que levam a doenças do trabalho, finalizando em prejudicar a tão sonhada produtividade almejada.

Necessitam-se de soluções para criação de empregos, para se chegar ao fim da fome e da miséria, para estancar a violência contra o meio ambiente, ou seja, para impor limites ao capitalismo e à globalização, sendo que apenas encontrando essas soluções poderemos minimizar efetivamente a ocorrência de afrontas ao direito de intimidade e de privacidade do empregado.

Necessita-se ter em nossa mente que os Direitos de Privacidade e de Intimidade do empregado pode e deve existir sempre em harmonia com os Poderes do empregador, principalmente o Diretivo e o Fiscalizatório, e é possível que se tenha produtividade sem invadir o espaço de personalidade do empregado. 
Ainda, verifica-se que no Brasil a regulamentação jurídica específica sobre os Direitos de Personalidade, mas ainda se tem muitas dificuldades de sua melhor aplicação.

Em que pese esta existência de uma legislação específica, há que se lembrar que a Constituição de 1988 tem como princípio a dignidade da pessoa humana, cabendo assim, não apenas ao Judiciário e ao Legislativo a adoção de medidas punitivas e preventivas, mas também à toda população, aos sindicatos e a vontade política de conscientização da sociedade na importância da valoração da vida humana e não na sua degradação perversa e sem sentido.

Todos os cidadãos devem praticar não mais o lema de que devemos tratar os outros como gostaríamos de ser tratados, mas sim pensar em como o outro gostaria de ser tratado em sua individualidade, em sua diferente cultura.

\section{REFERÊNCIAS}

ARISTÓTELES. Os pensadores. Tradução: Janice Florido. São Paulo: Editora Nova Cultural. 2000, p. 166-167.

BARROS, Alice Monteiro de. Proteção à intimidade do empregado. São Paulo: LTr, 1997.

BARROSO, Luís Roberto. A nova interpretação constitucional: ponderação, direitos fundamentais e relações privadas. 3. ed. revista. Rio de Janeiro: Renovar, 2008.

- "Da falta de efetividade à judicialização excessiva: Direito à saúde, fornecimento gratuito de medicamentos e parâmetros para a atuação judicial". In: Revista de Direito Social, 34/11, abr.- jun. 2009, p. 5-13.

CALVO, Adriana. "O conflito entre o poder de direção da empresa e a intimidade/privacidade do empregado no ambiente de trabalho". Disponível em: https://www.google.com/\#q=\% E2\% 80\%9C....a+precariza\% C3\% A7\% C3\% A30\% 2C+al iada+\% $\mathrm{C3} \% \mathrm{~A} 0+$ alta+rotatividade+de+trabalhadores:+62\% $2 \mathrm{C82} \% 25+$ dos+trabalhado 
res+sem+carteira+assinada \% 2C+31\% 2C85\% 25+dos+trabalhadores+aut \% C3\% B4nom os+e+17\%2C47\% 25+dos+empregados+. Acessado em: 20 de setembro de 2016.

CAVALCANTI, Themistocles Brandão. Princípios gerais de direito público. 3. ed. Rio de Janeiro: Borsoi, 1966.

CLÈVE, Clèmerson Merlin. Atividade Legislativa do Poder Executivo. 3. ed. rev. atual. e ampl. São Paulo: Editora Revista dos Tribunais, 2011.

COMPARATO, Fábio Konder. A afirmação histórica dos direitos humanos. 3. ed. São Paulo: Saraiva, 2003, p. 12.

COUTINHO, Aldacy Rachid. "O impacto da crise econômica e seus reflexos sobre as relações de trabalho". Disponível em: http://72.14.205.104/search?q=cache:j_oseH6qLYcJ:www.calvo.pro.br/palestras/conflito _poder.pdf+significa+a+esfera+mais+\% C3\% ADntima,+mais+subjetiva+e+mais\&hl=ptBR\&ct=clnk\&cd=1\&gl=br. Acessado em: 20 de setembro de 2016.

DINIZ, Patricia D.; VILLATORE, Marco Antônio César. "O assédio moral, analisado sob uma perspectiva moderna, determina medidas preventivas inovadoras". In: Revista jurídica UNICURITIBA, v. 2, p. 185-211, 2012.

FERREIRA FILHO, Manoel Gonçalves. Direitos humanos fundamentais. 7. ed. São Paulo: Saraiva, 2005.

FREITAS, Cíntia; VILLATORE, Marco Antônio César. "Palavras e expressões dicionarizadas podem coibir, no trabalho, provável assédio moral nas mensagens eletrônicas". In: XVIII CONPEDI, 2009, Maringá. Anais do XVIII Encontro Nacional CONPEDI. Florianópolis: Fundação Boiteux, 2009. v. 1. p. 2.615-2.629.

GARCIA, Filipe Barbosa. "Meio ambiente do trabalho no contexto dos direitos humanos fundamentais e responsabilidade civil do empregador". In Revista de Direito do

Trabalho. Coordenador Domingos Sávio Zainaghi. Ano 35, nº 136, São Paulo: Revista dos Tribunais. 2009.

GOMES, Orlando. Introdução ao direito civil. 18. ed. Rio de Janeiro: Forense, 2000. 
GOMES, Dinaura Godinho Pimentel. "A garantia do acesso ao trabalho decente". In: Direito Internacional do Trabalho e a Organização Internacional do Trabalho: trabalho decente. Jouberto de Quadros Pessoa Cavalcante; Marco Antônio César Villatore (Coordenadores). São Paulo: Atlas, 2015, p. 33-42.

GUNTHER, Luiz Eduardo; ZORNIG, Cristina Maria Navarro. "O direito da personalidade do novo código civil e o direito do trabalho", in $\mathbf{O}$ impacto do novo código civil no direito do trabalho. José Affonso Dallegrave Neto; Luiz Eduardo Gunther (Coordenadores), São Paulo: LTr, 2003.

. "Tutela dos Direitos da Personalidade na Atividade Empresarial”. In: Tutela dos Direitos da Personalidade na Atividade Empresarial. Luiz Eduardo Gunther (Coord.). Curitiba: Juruá, 2008.

HASSON, Roland. "O Estado, a atividade econômica e a sociedade globalizada" in Estado \& Atividade Econômica - O Direito Laboral em Perspectiva. Coordenadores Marco Antônio Villatore e Roland Hasson. Curitiba: Juruá, 2007, p. 39-51.

KANT, Immanuel. Immanuel Kant: textos seletos. Tradução por Raimundo Vier e Floriano de Sousa Fernandes. 3. ed. Petrópolis: Vozes, 2005.

MELEK, Marcelo Ivan; GUNTHER, Luiz Eduardo. "Os direitos da personalidade aplicados na relação contratual trabalhista e o dano moral decorrente de suas violações". In: Marco Antônio César Villatore; Ronald Silka de Almeida (Org.). As aplicações do Direito de Personalidade ao Direito do Trabalho. Curitiba: Juruá, 2013.

MENDES, Gilmar Ferreira; COELHO, Inocêncio Mártires; BRANCO, Paulo Gustavo Gonet. Curso de Direito Constitucional. 2. ed. rev. e atual. São Paulo: Saraiva. 2008.

; BRANCO, Paulo Gustavo Gonet. Curso de direito constitucional. 9. ed. São Paulo: Saraiva, 2014.

MONTEIRO, Washington de Barros. Curso de Direito Civil. Parte geral. 21. ed. v. 1. São Paulo: Saraiva, 1982.

MONTENEGRO, Aline Ferreira; GOMES, Eduardo Biacchi. "As Alterações Estatais e a Eficácia dos Ditames Constitucionais”. In: CONCILIAÇÃO: o paradigma da 
conciliação como forma de solucionar conflitos. Rosemarie Diedrichs Pimpão; Luiz Eduardo Gunther (Coord.); Juliana Cristina Busnardo; Marco Antônio César Villatore; Willians Franklin Lira dos Santos (Org.). Curitiba: Instituto Memória Editora, 2013, v. 1, p. 129.

MORAES, Alexandre de. Direitos Humanos Fundamentais: teoria geral. 4. ed. São Paulo: Atlas, 2002.

MOTA, Leda Pereira. SPITZCOVSKI, Celso. Curso de direito constitucional. 5. ed. São Paulo: Editora Juarez de Oliveira, 2000.

ORGANIZAÇÃO INTERNACIONAL DO TRABALHO - Consultas feitas ao site da OIT www.ilo.org. Acessado em: 20 de setembro de 2016.

PASCHOAL, Antonio Edmilson. A Genealogia de Nietzsche. Curitiba: Champagnat, 2003.

PAULO, Vicente; ALEXANDRINO, Marcelo. Direito Administrativo Descomplicado. 20. ed. São Paulo: Método, 2012.

PIOVESAN, Flávia. Temas de direitos humanos. 5. ed., São Paulo: Saraiva, 2012.

ROMITA, Arion Sayão. Direitos Fundamentais nas Relações de Trabalho. São Paulo: LTr, 2005.

SCHIER, Paulo Ricardo. Filtragem constitucional: construindo uma nova dogmática jurídica. Porto Alegre: Sergio Antonio Fabris Editor, 1999.

SILVA, José Afonso da. Curso de direito constitucional positivo. 33. ed. São Paulo: Malheiros, 2010.

SIMÓN, Sandra Lia. A proteção constitucional da intimidade e da vida privada do empregado. São Paulo: LTr, 2000.

SÜSSEKIND, Arnaldo. Direito Internacional do Trabalho. 3. ed. São Paulo: LTr, 2000. 
THOME, Candy Florêncio. O princípio da igualdade de gênero e a participação das mulheres nas organizações sindicais de trabalhadores. In: Revista do Tribunal Regional do

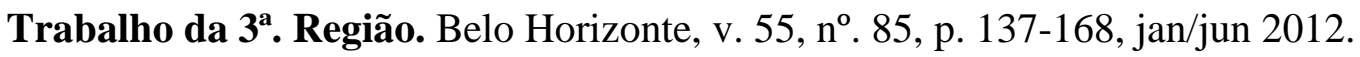

VILLATORE, Marco Antônio; ROCHA, Alexandre Euclides. "A atividade econômica do empregador em consonância com os direitos fundamentais dos empregados". In: Estado \& Atividade Econômica - O Direito Laboral em Perspectiva. Coordenadores Marco Antônio Villatore e Roland Hasson. Curitiba: Juruá, 2007, p. 151-178.

. “Consórcio Simplificado de Empregadores Rurais". Disponível em http://www.calvo.pro.br.artigo.marco_villatore_consorcio_simplificado.pdf. Acessado em 20 de setembro de 2016.

; BOSKOVIC, Alessandra Barichello. In: "Direito do Trabalho - XIV Jornada Luso-Hispano-Brasileira”. André Jobim de Azevedo; Marco Antônio César Villatore. Crise econômica: aspectos econômicos e sociais. Curitiba: Juruá. 2010, p. 49-77.

; ALMEIDA, Ronald Silka. "Conjecturas sobre o Direito de Personalidade e o Dano Moral no Ambiente de Trabalho". In: Marco Antônio César Villatore; Ronald Silka de Almeida (Org.). As aplicações do Direito de Personalidade ao Direito do Trabalho. Curitiba: Juruá, 2013, p. 111-132. 